\title{
A Method for Hydrofracture Propagation Control Based on Non-uniform Pore Pressure Field
}

\author{
Chenpeng Song 1,2, ${ }^{\text {, Yiyu Lu }}{ }^{3}$, Hongmei Tang ${ }^{1,2}$,Yunzhong Jia ${ }^{3,4}$ \\ ${ }^{1}$ Key Laboratory of Hydraulic and Waterway Engineering of the Ministry of Education, Chongqing \\ Jiaotong University, Chongqing 400074, China; \\ E-Mails:songchenpeng@163.com(C.S.); hmtang6778@sina.com(H.T.) \\ ${ }^{2}$ National Engineering Research Center for Inland Waterway Regulation, Chongqing Jiaotong University, \\ Chongqing 400074, China \\ ${ }^{3}$ State Key Laboratory of Coal Mine Disaster Dynamics and Control, Chongqing University,Chongqing \\ 400044, China; \\ E-Mails: luyiyu@cqu.edu.cn (Y.L.); yzj114@psu.edu(Y.J.) \\ ${ }^{4}$ EMS Energy Institute, Energy and Mineral Engineering \& G3 Center, The Pennsylvania State \\ University, University Park, PA 16802, USA \\ * Correspondence: songchenpeng@163.com(C.S.) \\ Tel.: +86-023-6510-6640(C.S.)
}

\begin{abstract}
Hydraulic fracturing technology, a technique for increasing productivity applicable in low-permeability oil-gas reservoir, has been used in the extraction of coal seam methane in underground coal mines. However, because of the more complex structure of coal seam compared with that of oil-gas reservoir, the hydrofracture propagation can easily extend to roof-floor rocks, limiting the range of permeability and making damages of roof-floor rocks in subsequent coal mining and support difficulty. How to control the hydrofracture propagation well-aligned in a large area of coal seam has become the key to long-time highly effective extraction of coal seam methane. Firstly, it starts with the perspective of stress field of crack tip, by means of thermal elasticity fracture mechanics theory, to get the stress intensity factor of hydrofracture tip while taking pore pressure into consideration. Next, a laboratory fracturing experiment using sandstone specimens was conducted to study the impact of non-uniform pore pressure on the direction of hydrofracture propagation. Lastly, a numerical simulation software RFPA ${ }^{2 D}-F l o w$ is adopted to further verify the theoretical and experimental results. The study shows that pore pressure can effectively increase the stress intensity factor of the crack tip, the more pressure of pore, the smaller the needed fluid pressure for hydrofracture propagation. In a large area, affected by the direction and distribution of pore pressure gradient, the hydrofracture will propagate along higher pore pressure area. A method is put forward for controlling hydrofracture propagation in underground coal mines accordingly. Meanwhile, the matching relationship between the space between boreholes and the water injection maintaining pressure and maintaining time are studied together, with methods and steps for calculating key fracture parameters established.
\end{abstract}

Keywords: hydraulic fracturing; coal seam; pore pressure; stress intensity factor; crack propagation

\section{Introduction}

China is rich in CBM (coal bed methane), with a located quantity of geological resource in coal bed reaching 36.81 trillion $\mathrm{m}^{3}$, making it the third biggest country in this regard[1,2]. To effectively extract CBM is an important part of the energy strategy and for achieving safe coal production in China. Nonetheless, the storage conditions for CBM are quite complex for over $70 \%$ of the coal seams are complicated and of low permeability, making the ground hydraulic fracturing technology for CBM extraction used in such major producing countries as the US, 
Russia and Australia inapplicable, as evidenced by the fact that ground extraction only accounted for $21.2 \%$ of the total extraction[3-5]. Currently, CBM extraction primarily takes place in underground, and such common permeability-increasing technologies as intensive drilling and hydraulic cutting, because of limited ability in increasing permeability, are bothered by problems like large drilling workload, low efficiency in extraction and long time of gas extraction[6-8].

In recent years, chinese scholars have proposed a method of increasing permeability in underground coal mine by referring to hydraulic fracturing principle in the field of oil and natural gas[9,10]. This method aims to crush the coal by pumping the high pressure water into coal bed through the drilling boreholes (from tunnels to coal seam), so as to expand and connect the existing cracks, form effective gas transport pathways, and thus improving the permeability in coal. micro-seismic monitoring in field hydraulic fracturing in coal mine indicates that the expansion of hydrofracture in its initial phase could effectively handle coal seam fracture, increasing permeability of coal seam. However, as coal seam is far less thick than oil-gas reservoir and hydrofracture affected by stress orientation and coal seam angle, will propagate to the interface between coal seam and roof and floor board stratum, and it will enter the stratum through the interface, making the scope of permeability-increasing limited and the support of roof and floor board difficult while mining the coal in later phase[11,12]. This will limit the strength of hydraulic fracturing method in its ability to pressure relief and increase permeability in a large spectrum. Thus, how to control the hydrofracture propagation well-aligned in a large spectrum of coal seam has become the key to hydraulic fracturing in underground coal mines.

As for the method for controlling hydrofracture propagation, fracturing for oil-gas reservoir and CBM ground is quite similar in techniques. The control method primarily uses horizontal drilling technology in which well track is effectively controlled by means of special downhole tools and measuring instruments, moving the drill towards the preset target through particular direction, which can substantially increase oil-gas production and reduce drilling cost[13-15]. Nevertheless, constrained by tunnel space and coal seam geological conditions, it is impossible to adopt the horizontal drilling technology for hydraulic fracturing in underground coal mines. Our research team has proposed "water jet assisted hydraulic crack control method" [16]. The method should be done as follows. Firstly, drilling a borehole in the coal seam and slotting with high pressure with water jet, this borehole was used to inject high pressure water. Then, four or more boreholes were drilled around the first borehole, these boreholes were also slotted by high pressure water jet. Finally, high pressure water will be injected into first borehole after sealing all boreholes. The slitting slotted by water jet could control crack initiation site and guide fracture's propagation. But the effect is limited in field application.Hence, finding a way to control hydrofracture propagation in underground coal mine is an impending science and technical issue that shall be seriously addressed for the increase of the range of fracture and the output of CBM.

Therefore, this research studies the impact of non-uniform pore pressure field on hydrofracture propagation by combining theoretical analysis and laboratory test in following ways. Firstly, it starts with the perspective of stress field of crack tip, by means of thermal elasticity fracture mechanics theory, to get the stress intensity factor of hydrofracture tip while taking pore pressure into consideration. Next, a laboratory fracturing experiment using sandstone specimens was conducted to study the impact of non-uniform pore pressure on the direction of hydrofracture propagation. Lastly, a numerical simulation software RFPA2D-Flow is adopted to further verify the theoretical and experimental results. A method for controlling hydrofracture based on pore pressure in underground coal mine was proposed according to the above mentioned analysis. Last, the matching relationship between the space between boreholes and the water injection maintaining pressure and maintaining time is studied, with key fracture parameters quantified.

\section{Stress Intensity Factor of Hydrofracture While Considering Pore Pressure}


When there is fluid in pores of coal, a poroelastic medium, the solid skeleton is affected by strength. This strength can be summed up as a volume force in which the force equals to grad $p$ and $p$ stands for the pore pressure in coal mass. Whereas it is necessary to point out that the volume force in elastic skeleton can not be attained through theoretic deduction, an analogy as follows can be applied: if fluid flow in the coal mass pores meets Darcy law, the volume force in the elastic skeleton can be achieved through classic thermoelastic theory[17,18]. Here, $p$ stands for $\alpha E T /(1-2 v)$ in the solution ( $\alpha$ is coefficient of thermal expansion, $E$ is elasticity modulus, $T$ is temperature, $v$ is Poisson's ratio)According to this analogy, we are considering applying thermal elasticity fracture mechanics to solve the crack problem of porous materials in the event of pore pressure. Firstly, we need to be clear about the stress intensity factor of crack under the conditions of the given temperature field.

We think about the following physical model: suppose we have an isolated disc-shaped fracture whose length is $2 a$. On lateral axis of the fracture (where $r<a, z=0)$ is the scope for heat-source distribution, as shown in Figure 1.

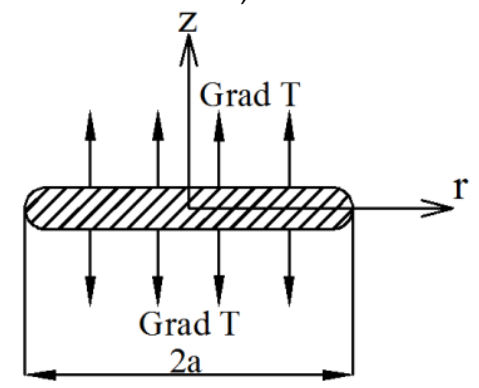

Figure 1. Fracture model

$$
\frac{\partial \theta(r, z)}{\partial r}=\left\{\begin{array}{ccc}
\frac{Q(r / a)}{\alpha} & \text { If } & 0<r<a, z=0 \\
0 & \text { If } & r>a, z=0
\end{array}\right.
$$

In the above formula, $\theta$ is the heat, $\alpha$ is the linear coefficient of thermal expansion, $a$ is the half-length of the fracture, $Q$ is the specific heat capacity and its unit is $\mathrm{J} /(\mathrm{m} \cdot \mathrm{K})$. To be clear, not as usual as $\mathrm{J} /(\mathrm{kg} \cdot \mathrm{K})$ to denote specific heat capacity. We used a similar expression $\mathrm{J} /(\mathrm{m} \bullet \mathrm{K})$. which means amount of heat per unit length(meter) required to raise the temperature by one degree Kelvin. With this, the stress intensity factor on the crack tip shall be[18]:

$$
K_{1}=-[(1+v) /(1-v)] \alpha T_{\infty} \sqrt{\pi a} \mu \int_{0}^{1} s Q(s) d s \quad K_{\mathrm{II}}=K_{\mathrm{III}}=0
$$

If a constant heat is given in fracture, to say, $\theta=\theta_{0}$, the following can be drawn from formula 2 ):

$$
K_{\mathrm{I}}=-\frac{2(1+v) \alpha T_{\infty} Q_{0} \sqrt{\pi a} \mu}{\pi(1-v)} \quad K_{\mathrm{II}}=K_{\mathrm{III}}=0
$$

In that way, we got the the stress intensity factor on the crack tip under the conditions of the given temperature field.

As mentioned above, stress intensity factor of hydrofracture under the condition of pore pressure is attained through the analogy. If in the unlimited porous space there is a $2 a$ long disc-shaped fracture where exists fluid whose constant pressure is $p_{w}$, the pore pressure of coal around the crack being $p_{0}$, the maximum horizontal principal stress of far field for the crack as $\sigma_{H}$, and the minimum horizontal principal stress is $\sigma_{h}$, as shown in Figure 2. 


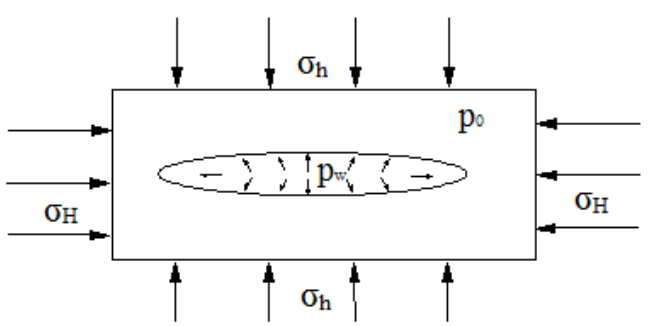

Figure 2. Model of hydrofracture propagation

Under the single pore pressure $p_{0}$ exercising the above-mentioned analogy with formula (3) could lead us to following stress intensity factor of crack tip:

$$
K_{\mathrm{I}}^{\prime}=\frac{1-2 v}{\pi(1-v)} p_{0} \sqrt{\pi a}
$$

In the event of cooperation force of far field stress filed and water pressure $p_{w}$ in the crack, normal stress $\sigma_{n}$ and shear stress $\tau_{n}$ on the crack by analyzing stress state are respectively :

$$
\begin{aligned}
& \sigma_{n}=p_{w}-\sigma_{h} \\
& \tau_{n}=0
\end{aligned}
$$

(5)

By formula (5), when propagating along the direction of the maximum horizontal stress $\sigma_{H}$, hydrofracture is only influenced by normal stress $\sigma_{n}$, the shear stress $\tau_{n}$ always remain zero. In accordance with fracture mechanics theories, the propagation instability of hydrofracture is the mode I crack problem. Based on the calculating formula of I-type crack stress intensity factor:

(6)

$$
K^{\prime \prime}=\sigma_{n} \sqrt{\pi a}
$$

Bringing the expression of $\sigma_{n}$ in formula (5) into (6) results in:

$$
K^{\prime \prime}=\left(p_{w}-\sigma_{h}\right) \sqrt{\pi a}
$$

According to superposition principles, superposing (4) and (7) can help us get stress intensity factor of hydrofracture under the condition of pore pressure, as follows:

$$
K_{1}^{\prime \prime \prime}=\left(p_{w}-\sigma_{h}\right) \sqrt{\pi a}+\frac{1-2 v}{\pi(1-v)} p_{0} \sqrt{\pi a}
$$

As shown in formula (8), volume force takes shape on the coal because of the existence of pore pressure near the crack tip, adding $[(1-2 v) / \pi(1-v)] p_{0} \sqrt{\pi a}$ caused by pore pressure to stress intensity factor of the crack tip. On one hand, the needed fluid pressure for propagation is reduced due to the impact of pore pressure near the crack tip; one the other hand, in a bigger scope, pore pressure gradient field will affect direction of crack. Because of the self-organizing behavior of crack propagation, Pore pressure gradient field will lead hydrofracture to propagate along the high pore pressure, in order to reduce the needed fluid pressure for propagation. Thus, it is theoretically feasible to control the propagation direction as well as reduce the pumping pressure by changing pore pressure distribution. In the next part, we conduct a laboratory hydraulic fracturing experiment to further verify the conclusion, and more importantly, a new way could be put forward for controlling hydrofracture propagation in underground coal mines. 


\section{An Experiment on Impact of Non-uniform Pore Pressure Field on Hydrofracture Propagation}

As is shown before, non-uniform pore pressure field will force the hydrofracture to propagate towards high pore pressure area. In the this part, we conduct laboratory hydraulic fracturing experiments to verify the conclusion.

We use cuboid sandstone specimen of the size $100 \mathrm{~mm} \times 100 \mathrm{~mm} \times 200 \mathrm{~mm}$, on whose surface two boreholes being $55 \mathrm{~mm}$ in-depth will be drilled. Of the two, $1 \#$ is the hydrofracture hole. In order for the fracture to propagate vertically, a $2 \mathrm{~mm}$ deep slot will be carved straight down at the bottom of $1 \#$. Before fracturing the $1 \#$, the fluid is injected into $2 \#$ at a constant pressure so that a local high pore pressure area around 2\# will be formed, as shown Figure 3.For the specimen, the unidirectional stress only takes place vertically.

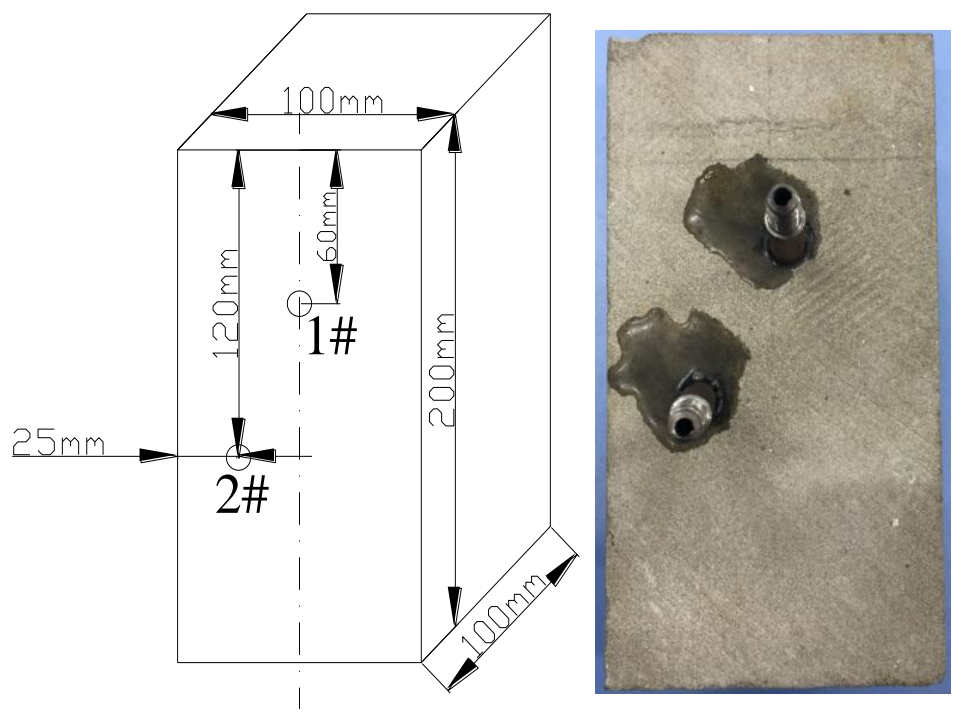

Figure 3.Sandstone specimen size

The schematic diagram of the experiment is shown in Figure 4.We use ordinary rock mechanical test system for axial loading devices (Figure 5). The type of pump is ISCO 260D dual syringe pump (Figure 6). This pump, 266ml in volume, is able to provide a maximum pressure of $51.7 \mathrm{MPa}(7500 \mathrm{psi})$. The work mode can adopt constant-pressure control or constant-flow control, and we use later mode for fracturing hole and former mode for water injection hole. The fluid is distilled water.

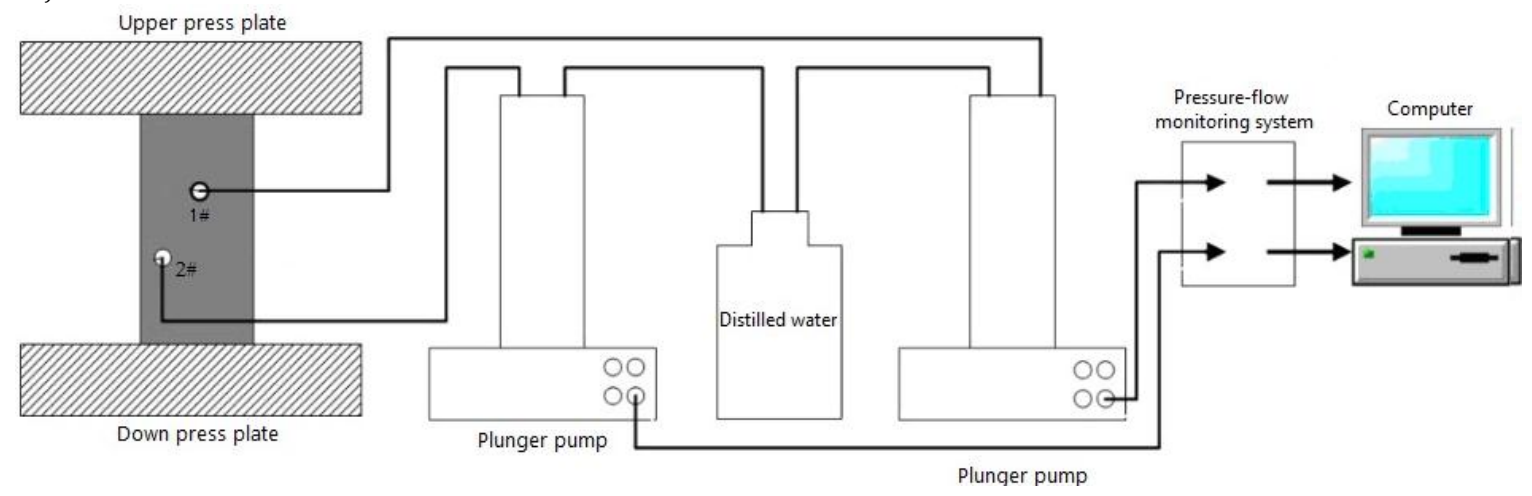

Figure 4. Schematic diagram of the experiment 


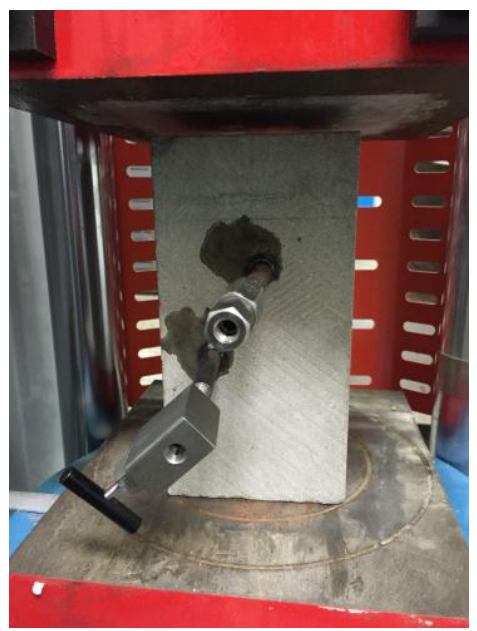

Figure 5. Axial Loading Devices

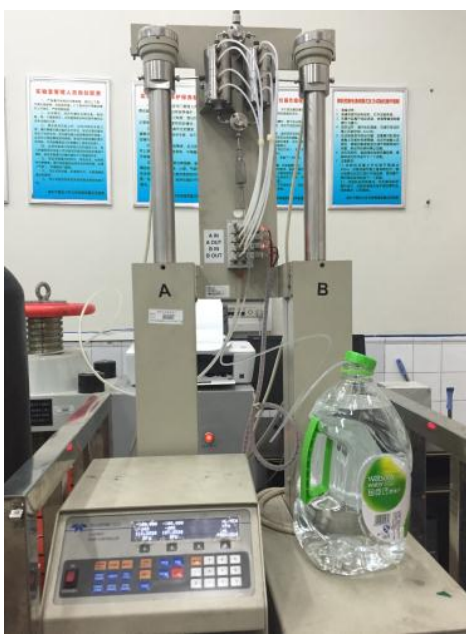

Figure 6. ISCO 260D dual syringe pump

As shown in Table.1, five groups of experiments are conducted.

Table.1 Experimental group table

\begin{tabular}{ccc}
\hline Number & Axial Pressure/MPa & 2\# Pressure/ MPa \\
\hline 1 & 10 & 0 \\
2 & 10 & 2 \\
3 & 10 & 4 \\
4 & 10 & 6 \\
5 & 10 & 8 \\
\hline
\end{tabular}

As the experiment is finished, the crack propagation results are shown in Figure 7.And the pressure curve of $1 \#$ borehole are shown in Figure 8.
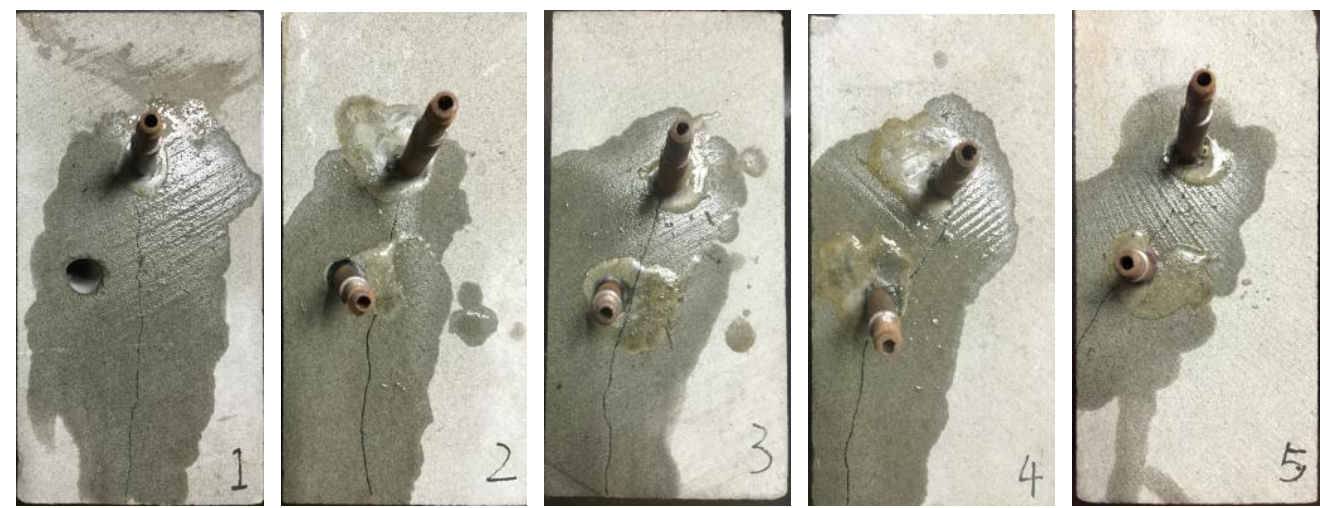

Figure 7. Crack propagation results 


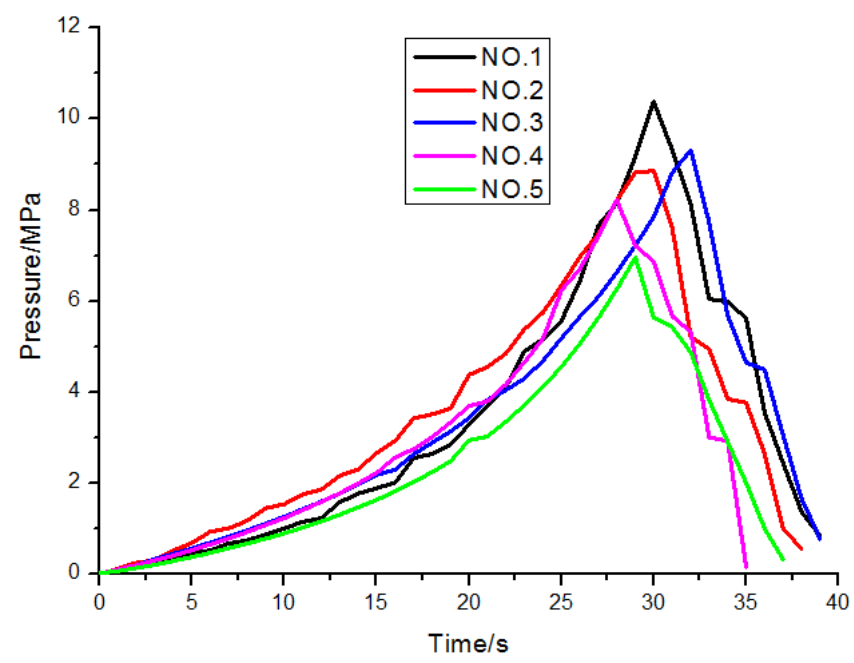

Figure 8. The pressure curve of $1 \#$

According to basic hydraulic fracturing theory, the hydrofracture propagation is a kind of tensile failure caused by the minimum principal stress. In the first group of experiment, the hydrofracture will propagate along the direction perpendicular to the maximum tensile stress when hole 2\# is without any constant water pressure. However, in groups 2 to 5 where there are different constant water pressures in hole $2 \#$, a pressure increasing area is formed because of the pressure gradient around hole 2\# caused by rock permeation. Meanwhile, with the increase of water pressure in hole $1 \#$ comes the strengthening of the pressure increasing area around hole $2 \#$, creating the maximum tension stress in the direction perpendicular to line between hole $1 \#$ and hole $2 \#$, and leading hydrofracture propagate towards hole 2\#. Also, the higher the constant water pressure are, the more evident the asymmetric trend becomes, and the more control it exerts on crack direction. At the same time, we also find that when horizontal principal stress difference is same, the constant water pressure in hole $2 \#$ increases whereas the instability propagation pressure of crack in hole 1 \# decreases, which is primarily due to the asymmetric distribution of pore pressure of the specimen created by water pressure gradient of the pore between hole $1 \#$ and $2 \#$. The bigger the water pressure in hole $2 \#$ is, the stronger the asymmetric trend of pore pressure will become, resulting in the impact on hydrofracture being more notable.

\section{Numerical simulation}

To further analyze the trend of the hydrofracture propagation under the effect of pore pressure gradient, a numerical simulation software RFPA2D-Flow is adopted to study it when considering the different pore pressure gradient and principal stress.

The coupling system of flow \& solid in rock failure process analysis (RFPA ${ }^{2 \mathrm{D}-F l o w}$ ) is a numerical simulation method developed by Professor Tang.C.A[19,20]. On the basis of nonlinearity, heterogeneity and anisotropy in rock fracturing. Its computing method is based on the finite element theory and statistical damage theory which the heterogeneity of material property and the randomness of flaw distribution are taken into consideration. Besides, the statistical distributional hypothesis for material property is applied to numerical computation method (finite element method) by damaging the element which meets the given strength criterion so that the numerical simulation of heterogeneity in material damaging process will be realized.

RFPA ${ }^{2 D}-F l o w$ is based on the following hypotheses: (1) The fluid in rock medium follows Biot seepage theory; (2) The rock medium is an elastic-brittle material with residual strength that its loading and unloading process meets elastic damage theory; (3) The maximum tensile strength criterion and Mohr-Coulomb criterion are used as damage threshold to judge element damage; (4) Under elastic state, the stress-permeability coefficient 
relationship for material is described by negative exponential function and the permeability coefficient will be increased dramatically after material damaged; (5) The mechanical parameter of material meso-structure is assigned according to Weibull distribution with the purpose of bringing in material heterogeneity[21].

In classic coupled seepage theory, the change of rock permeability caused by stress is without consideration, which does not meet momentum conservation. After taking the influence of stress into consideration, the coupled seepage and stress equation shall be provided. Therefore, the RFPA ${ }^{2 \mathrm{D}}$-Flow model with damage is as follows [20]:

Equilibrium equation: $\sigma_{i j, j}+\rho X_{j}=0 \quad(i, j=1,2,3)$

Geometric equation: $\varepsilon_{i j}=\frac{\left(u_{i, j}+u_{j, i}\right)}{2} \quad \varepsilon_{v}=\varepsilon_{11}+\varepsilon_{22}+\varepsilon_{33}$

Constitutive equation: $\sigma_{i j}{ }^{\prime}=\sigma_{i j}-\alpha p_{0} \delta_{i j}=\lambda \delta_{i j} \varepsilon_{v}+2 G \varepsilon_{i j}$

Seepage equation: $K \nabla^{2} p_{0}=\frac{1}{Q} \frac{\partial p_{0}}{\partial t}-\alpha \frac{\partial \varepsilon_{v}}{\partial t}$

Coupled seepage and stress equation: $K\left(\sigma, p_{0}\right)=\xi K_{0} e^{-\beta\left(\sigma_{i j} / 3-\alpha p_{0}\right)}$

In those equations: $\rho$ is physical density; $\sigma_{i j}$ is the sum of normal stress; $\varepsilon_{v}$ and $\varepsilon_{i j}$ represent volumetric strain and normal strain respectively; $Q$ represents Biot constant; $G$ and $\lambda$ represent shear modulus and Lame coefficient; $\nabla^{2}$ means Laplace operator; $K_{0}$ and $\mathrm{K}$ represent initial-value of seepage coefficient and seepage coefficient respectively; $P_{0}$ is pore water pressure. $\xi, \alpha$ and $\beta$ represent mutation ratio of seepage coefficient, pore water pressure coefficient and coupling coefficient (stress sensitivity factor) separately which are determined through experiment.

When stress state or strain state of element meet some given damage thresholds, the element will start to damage. The elasticity modulus of damage element is : $E=(1-D) E_{0}$, of which $D$ represents damage variable, E and E0 represent the elasticity modulus of damage element and non-damage element respectively. Those parameters are assumed to be scalars.

A $200 \mathrm{~mm} \times 200 \mathrm{~mm}$ rectangular area in which $300 \times 300=90000$ units are distributed is set with a plane strain model. The model is not restrained in its boundaries except its fixed base. Value of the mechanical parameters of the materials is demonstrated in Table.2. In the model, there are two boreholes as same as the sandstone hydraulic fracturing test. The unidirectional stress only takes place vertically as well. Water pressure in pore $1 \#$ increases by $0.2 \mathrm{MPa}$ step size and the initial water pressure depend on the initial boundary conditions. To further analysis crack propagation trend under the combined impact of pressure gradient and the horizontal differential principal stress, we set nine groups of simulations. Table. 3 shows the parameters of constant water pressure in pore $2 \#$ and axial pressure. We know from the previous analysis that the greater the constant water pressure in $2 \#$, the stronger strength it has with the control on the crack. Also, the bigger the horizontal differential principal stress is, the more evidently the trend of the crack propagation moves towards the maximum principal stress direction, which will contribute to the competition between the two forces in their impact on the crack propagation direction.

Table. 2 Mechanical parameters

$\begin{array}{llll}\text { Mechanical parameters } & \text { value } & \text { Mechanical parameters }\end{array}$




\begin{tabular}{cccc}
\hline Heterogeneity & 10 & $\begin{array}{c}\text { Permeability increase multiple } \\
\text { after damage }\end{array}$ & 100 \\
Elasticity modulus/MPa & 35000 & $\begin{array}{c}\text { Pore water pressure coefficient } \\
\text { after damage }\end{array}$ & 1 \\
$\begin{array}{c}\text { Residual strength } \\
\text { coefficients }\end{array}$ & 0.1 & Coupling coefficient & 0.1 \\
Compression strength/MPa & 60 & Pore water pressure coefficient & 0.1 \\
Poisson ratio & 0.3 & Permeability coefficient/(m/d) & 0.2 \\
\hline
\end{tabular}

Table. 3 The parameters of the horizontal differential principal stress and constant pressure

\begin{tabular}{ccc}
\hline Number & Axial Pressure/MPa & 2\# Pressure/ MPa \\
\hline 1 & 5 & 8 \\
2 & 5 & 4 \\
3 & 5 & 2 \\
4 & 10 & 8 \\
5 & 10 & 4 \\
6 & 10 & 2 \\
7 & 15 & 8 \\
8 & 15 & 4 \\
9 & 15 & 2 \\
\hline
\end{tabular}

As shown in Figure 9, the red area stands for the high pore pressure area, while the blue stands for the low. The result is that when the crack begins along axial pressure, it will gradually move towards $2 \#$. The greater the constant pressure is, the bigger the asymmetric trend of the pressure gradient, and the greater control it has over the crack propagation. However, the bigger stress difference will weaken the control capacity of the pore pressure gradient around $2 \#$ on the crack. At the same time, it is note worthy that given the certain stress difference. If the greater the constant pressure in $2 \#$, there will be a smaller the propagation pressure(the maximum propagation pressure of nine groups is shown in Table.4). This is because of the asymmetric distribution of pore pressure in the model caused by pore water pressure gradient between $1 \#$ and $2 \#$. The greater the water pressure in $2 \#$ is, the stronger the asymmetric distribution of pore pressure is, the greater impact it has on the crack.
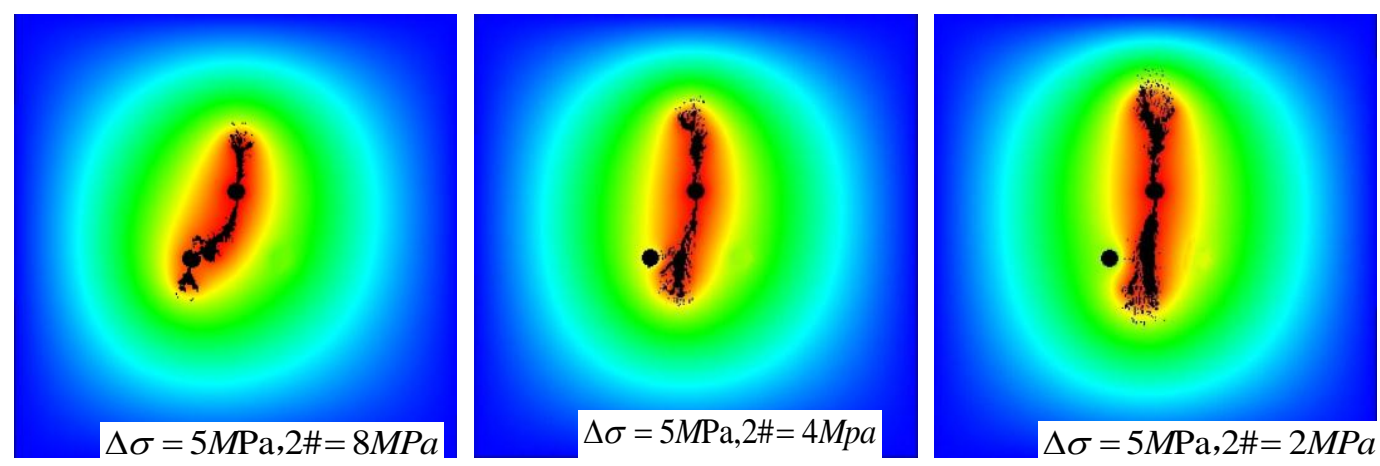

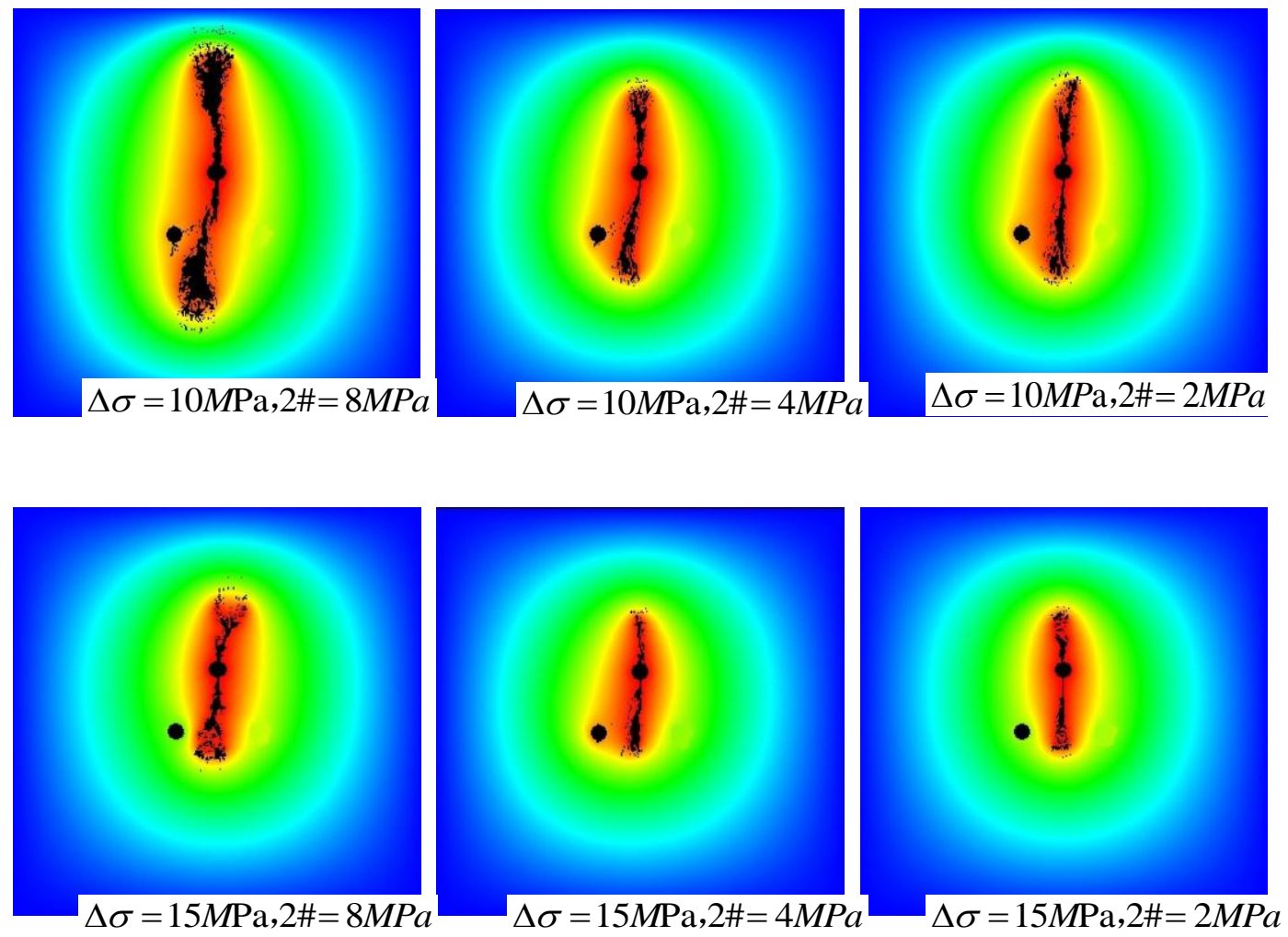

Figure 9. The process of hydraulic fracture pore pressure figure

Table.4 the maximum propagation pressure of nine groups

\begin{tabular}{cc}
\hline Number & The maximum propagation pressure /MPa \\
\hline 1 & 4.2 \\
2 & 7.2 \\
3 & 9.0 \\
4 & 7.2 \\
5 & 8.8 \\
6 & 9.8 \\
7 & 8.4 \\
8 & 9.2 \\
9 & 10.2 \\
\hline
\end{tabular}

The numerical simulation, theoretical analysis and experiment show nearly the same result, which means when crustal stress is certain, changes in distribution of pore pressure of coal mass around the hydrofracture can control the hydrofracture in its propagation towards high pore pressure area, with the needed water pressure in this process being reduced. Therefore, based on the above result, we propose a method of multiple boreholes cooperation guiding hydrofracture propagation in underground coal mines. Before the beginning of formal hydraulic fracturing, we preset several pressure maintaining water injection boreholes along the predetermined propagation direction on both sides of the hydraulic fracturing borehole. This is to increase the pore pressure of the coal around by maintaining pressure through water injection, and form a continuous strap-shaped high pore pressure area, which could, on one hand, guide the hydrofracture to propagate along the preset direction and 
expand the range of effective hydraulic fracturing, and reduce the propagation pressure of the hydrofracture hole on the other hand, as shown in Figure 10.

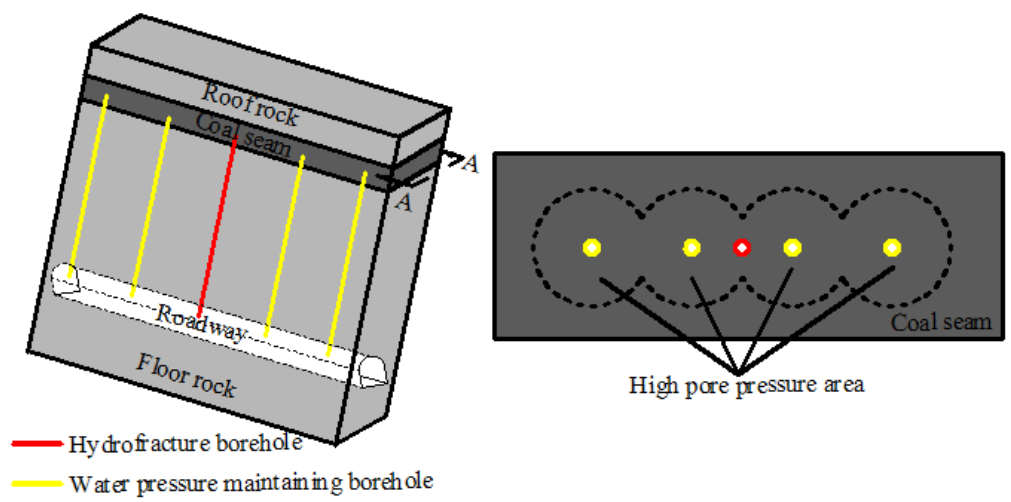

Figure 10. Sketch map of multiple-boreholes cooperation hydrofracture

\section{A Study on the Multiple-boreholes Cooperation Hydrofracture Technology Parameters in Underground Coal Mine}

Parameters involved in the multiple-boreholes cooperation hydrofracture technology are primarily about selecting the parameters in such areas as ways of drilling holes arrangement, the water injection maintaining pressure and maintaining time. Of them, parameters of drilling holes involve angle, hole height, diameter and space between boreholes. To be more specific, determining drilling angle follows the rules of being vertical coal seam plane; hole height is determined by roadway size and the type of drilling machine. The aforementioned study shows distribution of pore pressure in the coal has impact on hydrofracture propagates towards high pore pressure gradient direction. Therefore, arranging several pressure maintaining water injection holes on both sides of the hydrofracture holes and forming a continuous strap-shaped high pore pressure area could lead hydrofracture move along the neighboring drilling lines. It is, therefore, necessary to study the matching relationship among the drill holes spacing, the water injection maintaining pressure and maintaining time.

Because of the original gas pressure in coal, we can take water injection process as displacement of coal bed methane by fluid. In the coal seam, the process of water flow is consider as one dimensional radial flow problem. Suppose the wetting radius of coal seam is $R$, while that of drilling hole is $r_{w}$, and gas-liquid interface being $r_{c}$. According to Darcy law and without considering the gravity and compressibility of fluid, the displacement of gas-liquid interface with time can be expressed as[22]:

$$
y=r_{w}+r_{c}(t)
$$

The speed of gas-liquid interface is:

$$
\begin{gathered}
\frac{d y}{d t}=\frac{\partial y}{\partial t}+u \frac{\partial y}{\partial r} \\
u=\frac{d r_{c}}{d t}
\end{gathered}
$$

If porosity of coal seam remains constant when injecting water, the seepage equations for liquid and gas area can be shown as:

$$
\frac{\partial^{2} p_{1}}{\partial r^{2}}+\frac{1}{r} \frac{\partial p_{1}}{\partial r}=0 \quad r_{w}<r<r_{c}
$$




$$
\frac{\partial^{2} p_{2}}{\partial r^{2}}+\frac{1}{r} \frac{\partial p_{2}}{\partial r}=0 \quad r_{c}<r<R
$$

In formula (12) and (13), $p_{1}$ is the liquid area pressure distribution, while $p_{2}$ is for gas area.

Based on the continuity of the seepage velocity and pressure distribution on the gas-liquid interface, as well as boundary conditions.

$$
\begin{gathered}
p_{1}=p_{w} \quad r=r_{w} \\
p_{2}=p_{g} \quad r=R \\
p_{1}=p_{2}=p_{u} \quad r=r_{c} \\
\frac{1}{\mu_{w}} \frac{\partial p_{1}}{\partial r}=\frac{1}{\mu_{g}} \frac{\partial p_{2}}{\partial r} \quad r=r_{c}
\end{gathered}
$$

$p_{w}$ stands for water injection pressure, $p_{g}$ is the original gas pressure, $p_{u}$ is the gas-liquid interface pressure, $\mu_{w}$ for coefficient of viscosity of water, $\mu_{g}$ for coefficient of viscosity of gas.

Thus, the pressure distribution and seepage velocity of liquid and gas areas can be attained by[23]:

Pressure distribution of liquid is:

$$
p_{1}=p_{w}+\frac{p_{w}-p_{u}}{\ln \frac{r_{w}}{r_{c}}} \ln \frac{r}{r_{w}}
$$

Seepage velocity of liquid area is:

$$
u_{w}=\frac{k}{\mu_{w}} \frac{d p_{1}}{d r}=\frac{k\left(p_{w}-p_{u}\right)}{\mu_{w} r \ln \frac{r_{w}}{r_{c}}}
$$

Pressure distribution of gas area is:

$$
p_{2}=p_{g}+\frac{p_{u}-p_{g}}{\ln \frac{r_{c}}{R}} \ln \frac{r}{R}
$$

Seepage velocity of liquid area is:

$$
u_{g}=\frac{k}{\mu_{g}} \frac{d p_{g}}{d r}=\frac{k\left(p_{u}-p_{g}\right)}{\mu_{g} r \ln \frac{r_{c}}{R}}
$$

Of them, $p_{u}$ is the gas-liquid interface pressure: 


$$
p_{u}=\frac{\mu_{g} \ln \frac{r_{c}}{R} p_{w}+\mu_{w} \ln \frac{r_{w}}{r_{c}} p_{g}}{\mu_{g} r \ln \frac{r_{c}}{R}+\mu_{w} \ln \frac{r_{w}}{r_{c}}}
$$

According to material derivative and seepage velocity of gas-liquid interface, it is consistent with Dupuit-Forchheimer relation[24]:

$$
u=\phi \frac{d r_{c}}{d t}
$$

Thus, we can get the time it takes for gas-liquid interface to move to R:

$$
t=\frac{\phi}{k\left(p_{w}-p_{g}\right)} \int_{r_{w}}^{R}\left(\mu_{g}-\mu_{w}\right) r_{c}{ }^{2} \ln r_{c}\left(\mu_{w} \ln r_{c}-\mu_{g} \ln R\right) d r_{c}
$$

Therefore, formula (24) is the needed time for pressure maintaining water injection when the space between holes is $2 \mathrm{R}$.

The value of water injection pressure must be greater than the original gas pressure but less than initiation fracture pressure in the coal seam, which means:

$$
p_{g}<p_{w}<p_{b}
$$

In formula (25), $p_{b}$ is the initiation pressure of the coal seam, which can be calculated through the fracture criterion based on the theory "tensile fracture induced by stress concentration of hole wall" put forward by Hubbert[25]:

$$
p_{b}=3 \sigma_{h}-\sigma_{H}+S_{t}
$$

In this formula, $\sigma_{\mathrm{H}}$ and $\sigma_{\mathrm{h}}$ are the maximum and minimum horizontal main crustal stresses respectively.

Values of $\sigma_{\mathrm{H}}$ and $\sigma_{\mathrm{h}}$ are determined by following formulas where the maximum and minimum horizontal main crustal stresses change with the depth, which was found by O.Stephansson et al in their field measurements[26]:

$$
\begin{gathered}
\sigma_{\mathrm{H}}=6.7+0.0444 \mathrm{H}(\mathrm{MPa}) \\
\sigma_{\mathrm{h}}=0.8+0.0329 \mathrm{H}(\mathrm{MPa})
\end{gathered}
$$

In this formula, $\mathrm{H}$ is the depth/m .

As a result, based on the study on the matching relationship among the borehole spaceing, the water injection maintaining pressure and maintaining time. Parameters of multiple-boreholes cooperation hydrofracture technology are determined by taking following steps:

(1) Firstly, we determine the place of hydraulic fracturing drilling hole and the drilling parameters based on fracking areas as well as coal seam geology.

(2) On both sides of hydraulic fracturing drilling hole, the pressure maintaining water injection drilling holes are arranged according to the principle of equal spaces. Based on experience, the space between these drilling holes shall be less than $20 \mathrm{~m}$.

(3) According to formulas (25)-(27), we determine the water injection pressure of pressure maintaining drilling holes, and if the greater the water injection pressure is, the more controlling power it exerts on hydrofracture direction.

(4) Based on the determined spaces between drilling holes and the water injection pressure of pressure maintaining drilling holes, we can confirm the needed time for pressure maintaining water injection through formula (24). 


\section{Conclusions :}

This research studies the impact mechanism of pore pressure fields on hydrofracture propagation by theoretical analysis, laboratory test and numerical simulation . The study shows that pore pressure can effectively increase the stress intensity factor of the hydrofracture tip, the more pressure of pore, the smaller the needed water pressure for hydrofracture propagation. In a large areas, affected by the direction and distribution of pore pressure gradient, the hydrofracture will propagate along the high pressure area.

A method is put forward for controlling hydrofracture propagation in underground coal mines. We preset several pressure maintaining water injection drill holes along the predetermined hydrofracture propagation direction on both sides of the hydrofracture drill hole. This is to form a continuous strap-shaped high pore pressure area on both sides the fracture drilling hole, which could guide the hydrofracture to propagate along the preset direction and expand the range of effective hydrofracture, and reduce the hydrofracture propagation pressure .

Meanwhile, based on Darcy seepage theory, the matching relationship among the drill holes spacing, the water injection maintaining pressure and maintaining time in the multiple-boreholes cooperation hydrofracture technology is studied, with methods and steps for calculating key fracture parameters established.

\section{Acknowledgments:}

This paper is jointly supported by 973 Program (NO. 2014CB239206) ,PCSIRT (NO. IRT13043 ) , the National Science Foundation of China (NO.51374258;NO.51409027;NO.51378521; NO.51408084).

\section{Author Contributions:}

Chenpeng Song and Yiyu Lu conceived and designed the article; Hongmei Tang and Yunzhong Jia performed the experiments; Chenpeng Song analyzed the data and wrote the paper.

\section{Conflicts of Interest:}

The authors declare no conflict of interest.

\section{References`}

1. Li, H. Major and minor structural features of a bedding shear zone along a coal seam and related gas outburst, Pingdingshan coalfield, northern China. Energ Fuel Abstr. 2002, $43(4), 246$.

2. Li, X.Z.; Hua, A.Z. Prediction and prevention of sandstone-gas outbursts in coal mines. Int. J. Rock Mech Min.2006, 43(1),2-18.

3. Li, X.H.; Lu, Y.Y.; Zhou, Y.; Kang, Y.; Zhou, D.P. Study on improving the permeability of soft coal Seam with high pressure pulsed water jet. J. China Coal Soc.2008, 33(12), 1386-1390.

4. Guo, P.; Cheng, Y.; Jin, K.; Liu, Y. The impact of faults on the occurrence of coal bed methane in renlou coal mine, huaibei coalfield, china. J. Nat Gas Sci Eng. 2014, 17(2), 151-158.

5. Lu, Y.Y.; Liu, Y.; Li, X.H.; Kang, Y. A new method of drilling long boreholes in low permeability coal by improving its permeability. Int. J. Coal Geol. 2010, 84, 94-102.

6. Liu, J.; Chen, Z.; Elsworth, D.; Qu, H.; Chen, D. Interactions of multiple processes during CBM extraction: a critical review. In. J. Coal Geol. 2011, 87(s3-4), 175-189.

7. Herckenrath, D.; Doherty, J.; Panday, S. Incorporating the effect of gas in modelling the impact of cbm extraction on regional groundwater systems. J. Hydrol. 2015, 523, 587-601.

8. Wang, H.; Cheng, Y.; Wang, W.; Xu, R. Research on comprehensive CBM extraction technology and its applications in china's coal mines. J. Nat Gas Sci Eng. 2014, 20(20), 200-207.

9. Song, C.; Lu, Y.; Jia, Y.; Xia, B. Effect of interface of coal seam and rock stratum on 
hydraulic fracture propagation.J.Chongqing univ.2014, 35(9), 1340-1345.

10. Song, C.; Lu, Y.; Xia, B. Effects of natural fractures on hydraulic fractures propagation of coal seams. J. Northeastern univ. 2014, 35(5):756-760.

11. Hanson, M.E.; Shaffer, R.J.; Hanson, M.E.; Shaffer, R.J. Some results from continuum mechanics analyses of the hydraulic fracturing process. SPE. 1980, 20(2), 86-94.

12. Anderson, G. D. Effects of friction on hydraulic fracture growth near unbonded interfaces in rocks. SPE. 1981, 21(1), 21-29.

13. Lu, Y.; Song, C.; Jia, Y.; Xia, B.; Ge, Z.; Tang, J. Analysis and numerical simulation of hydrofracture crack propagation in coal-rock bed. CMES-Comp Model Eng, 2015, 105, 69-86.

14. Noritis. Horizontal drilling technology keeps advancing. Oil Gas. J. 1991, 89, 49-54.

15. Minegases; Miningindustry; Methanes; Methanedrainage; Methanecontrol; Explosivegases. Review of horizontal drilling technology for methane drainage from us coal beds. Inf. Circ. - U.S., Bur. Mines. 1980, 8829.

16. Xia, B.; Ke, H.; Lu, Y. Mechanism of crack-oriented of hydraulic fracture and its technique in mine. J of Chongqing Univ., 2013, 36(9),8-13.

17. Detournay, E.; Cheng, H.D.; Roegiers, J.C.; Mclennan, J.D. Poroelasticity considerations in situ stress determination by hydraulic fracturing. Int. J. Rock Mech Min Geomech Abstr. 1989, 26(6), 507-513.

18. Cherepanov, G. P. Mechanics of brittle fracture. Int. J. Appl Mech. 1979, 49(4):673-674.

19. Tang, C. A. Numerical simulation of progressive rock failure and associated Seismicity. Int. J. Rock Mech Min. 1997, 34,249-261.

20. Tang, C. A. A new approach to numerical method of modelling geological processes and rock engineering problems. Eng Geol .1998, 49, 207-214.

21. Tang, C. A.; Kaiser, P. K. Numerical simulation of cumulative ddamage and seismic energy release during brittle rock failure - Part I: fundamentals. Int. J. Rock Mech Min. 1998, 35(2),113-121.

22. Nathanson, G.M.; Davidovits, P.; Worsnop, D.R.; Kolb, C.E. Dynamics and kinetics at the gas-liquid interface. J. Phys Chem. 1996, 100(31), 13007-13020.

23. Kovacs, G. Seepage hydraulics. Amsterdam, Elsevier, 1981.

24. Bear, J.; Dagan, G. Some exact solutions of interface problems by means of the hodograph method. J. Geophys Res. 1964, 69(8), 1563-1572.

25. Rubey, W.W.; Hubbert, M.K. Role of fluid pressure in mechanics of overthrust faulting. Geol soc AM Bull. 1959, 70(2), 115.

26. Amadei, B.; Stephansson, O. Rock Stress and Its Measurement. Springer: Netherlands; pp. 101-105. 